\title{
Possible Connections between Seasons and Ultra-Deep Earthquakes Worldwide
}

\author{
Marilia Hagen ${ }^{1}$, A. Azevedo² \\ ${ }^{1}$ Universidade Federal Fluminense, Instituto de Fisica, Niteroi, RJ, Brazil (retired); ${ }^{2}$ Faculdade de Ciências Aplicadas \\ da Unicamp-R. Pedro Zaccaria, Limeira, São Paulo
}

Correspondence to: Marilia Hagen, marhagen@indiana.edu; A. Azevedo, anibal.azevedo@fca.unicamp.br

Keywords: Sun, Moon, Earth, Ultra-Deep Quakes, Seasons

Received: July 2, $2018 \quad$ Accepted: July 27, $2018 \quad$ Published: July 30, 2018

Copyright $\odot 2018$ by authors and Scientific Research Publishing Inc.

This work is licensed under the Creative Commons Attribution International License (CC BY 4.0).

http://creativecommons.org/licenses/by/4.0/

\section{(c) (i) Open Access}

\section{ABSTRACT}

The aim of this investigation is to find possible changes in ultra-deep earthquakes (UDQ) during different seasons of the year. In the acquisition of data for our previous work we observed an inexplicable pattern of growth of ultra-deep tremors (UDQ) during the studied period. Apparently, there is no viable explanation for growth occurring at such a level, presumably in the asthenosphere. Current research and theories developed for the inner layers of the Earth do not explain such variations. Therefore, a possible explanation would be in external factors such as the seasons of the year, which are determined by changes in the Earth's axial tilt, and therefore the portion of the earth that is angled toward the sun. This paper focuses exclusively on UDQ events. To simplify the calculations, we consider four main locations; this includes one more region than our previous paper but includes only UDQ data. The results showed that during spring and autumn UDQ events grew slightly in both Northern and Southern Hemispheres. It is also suggested that a contributor to UDQ events is friction from the subducting lithosphere against the continental plates.

\section{INTRODUCTION}

The purpose of this work is to continue evaluating possible connections between the Sun, Moon, and Earth [1-3]. Our examination of the effects of the Moon's gravitational forces at perigee has also been published [1]. In our previous papers we suggested the location of a possible slab in the asthenosphere situated along the Western edge of South America that contributed to not only deep but also ultra-deep earthquakes (DQ and UDQ) [4-6]. In this study, we trace the deepest seismic activities on the planet and their correspondence to changing seasons throughout the year. We also consider one more region than we did in our previous work. Anomalous or isolated deep seismicity occurrences in several other locations we describe here will be disregarded for the time being. In our last paper [4] our study comprised also the DQ earthquakes below or equal $100 \mathrm{~km}$ depth but only for UDQ $\geq 500 \mathrm{~km}$ depth we found out some anoma- 
lies which now, we are going to investigate.

We used the information for ultra-deep earthquakes $(\geq 500 \mathrm{~km})$ to find any enhancement of such events that correspond to the seasons, which are determined by the Earth's movement around the Sun. For seasonal changes, we need to consider the tilt of the Earth's axis at 23.5 degrees relative to its orbital plane, which causes variations in where the Sun's light hits the Earth. The inclination of the axis and the earth's position around the Sun result in asynchronous seasons in the Northern and Southern Hemisphere. Summer and maximum sunlight in the Southern hemisphere falls in January, while peak sunlight and the summer season in the Northern Hemisphere are in July. Spring and Fall in both hemispheres happen when the Sun's energy appears to be directed to the Earth's equator. March 20 or 21 defines the vernal equinox which marks the Spring in the Northern and Fall in the Southern Hemisphere. On September 22 or 23 the Earth reaches the autumnal equinox, indicating the arrival of Fall in the North and Spring in the South.

In the next section, we examine the occurrence of ultra-deep quakes worldwide. We consider four main regions that showed such activity: Northern Pacific, Philippines, Southern Pacific, and South America. The reason for considering the Philippines and South America separately is the exceptional behavior of the events in those areas, perhaps connected to the fact that the Philippines is located near the Equator and the UDQ events in South America are intraplate. We also detected UDQs in other locations around the world, but not in adequate numbers to allow any statistical study.

We considered UDQs with magnitude M2.5 or greater, according to data recorded in [7-9]. In our last paper ultra-deep events showed the greatest variations compared with other depths along the period analyzed, so we decided to focus on this depth range and the magnitudes dates were expanded to included events since M2.5.

\section{LOCATIONS OF ULTRA-DEEP EARTHQUAKES}

Figures 1-4 were created by the software from USGS data for earthquakes [7] the maps were constructed for events M2.5 or higher during the period 1980-2018. That was an extend period for those pictures defining the area with main concentration of UDQ episodes.

First, in the North Pacific area the events are concentrated along the west side of the Pacific, with the most active region ranging in the north around Russia, China, and Japan, to almost around the Equator with the Philippines. Figure 1 and Figure 2 show these two sub-regions. The occurrences further North are spread between the Sea of Okhotsk, Peter the Great Gulf (Russia), Sea of Japan, and below the Marianas islands (not pictured in Figure 1). Figure 2 shows the locations for the Philippines ultra-deep quakes, which are concentrated in the Celebes Sea. The Philippines region was examined separately because it is near the Equator and shows different behavior compared to the rest of the North Pacific. The Southern Pacific is shown in Figure 3; here we see some of the deepest quakes worldwide, which are localized in Vanuatu, with deeper UDQs being in Fiji where tremors can reach depths of $730 \mathrm{~km}$. The next sections we are going to discussing the forces at the Earth's surface as the seasons that perhaps are influencing those UDQs events.

\section{ULTRA-DEEP EARTHQUAKES AND SEASONS}

In our last paper we observed that at or below $500 \mathrm{~km}$ earthquakes occurrences show high discrepancies compared to shallower tremors. Therefore, we narrowed our focus in this study to consider only those more dynamic depth ranges.

The first objective in this study was to find the occurrences during the period 1999-2017. The main reason for this choice was the two solar maxima, in 2000 and 2014, which we have included in previous studies for consistency and to measure any effects of those unusual conditions [1,2]. At this point our search became more complicated because the seasons in the Northern hemisphere are the opposite of those in the Southern Hemisphere.

The coordinates defining the regions we studied are shown below in Table 1. The Northern hemisphere is defined by two locations: North Pacific and the Philippines. The Southern hemisphere includes Vanuatu, Fiji, New Zealand, part of Indonesia, Samoa, and finally the South America intraplate region. 


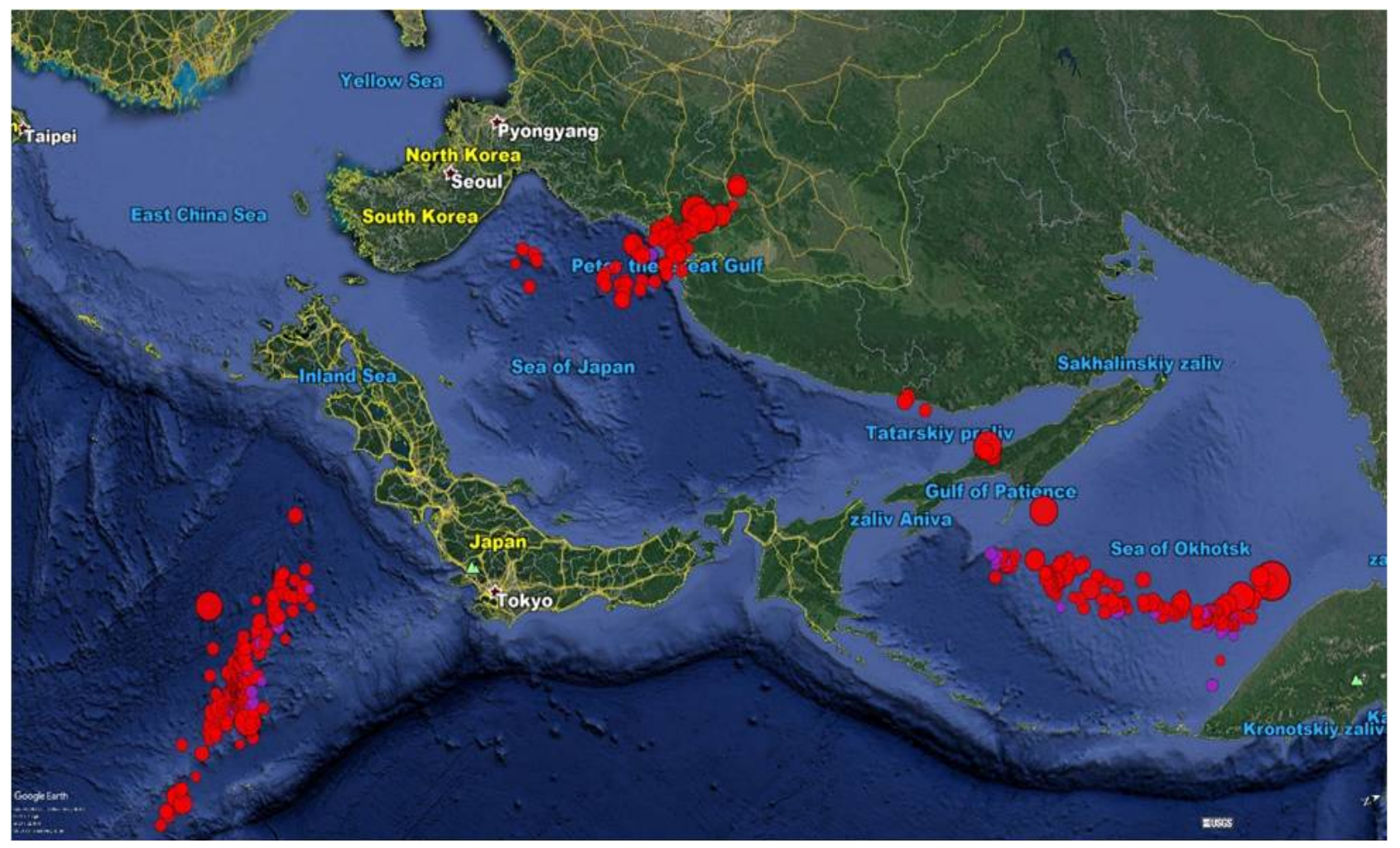

Figure 1. The Northern Pacific where occurring ultra-deep quakes. Purple dots are $500 \mathrm{~km}$ depth. The red dots are $>500 \mathrm{~km}$ depth.

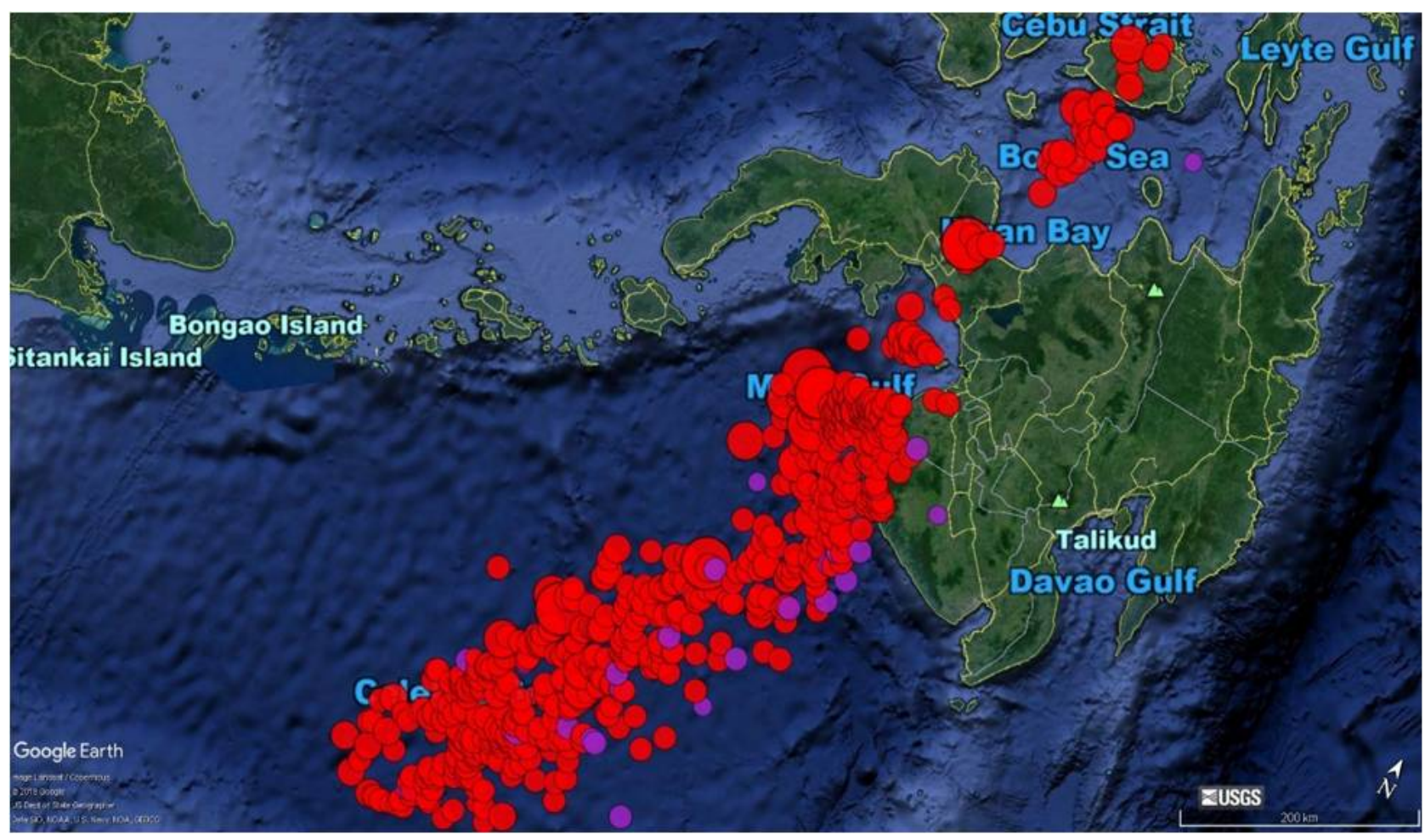

Figure 2. Philippines region with ultra-deep earthquakes. The depth is $\geq 500 \mathrm{~km}$, purple dots mean $500 \mathrm{~km}$, below are red. 


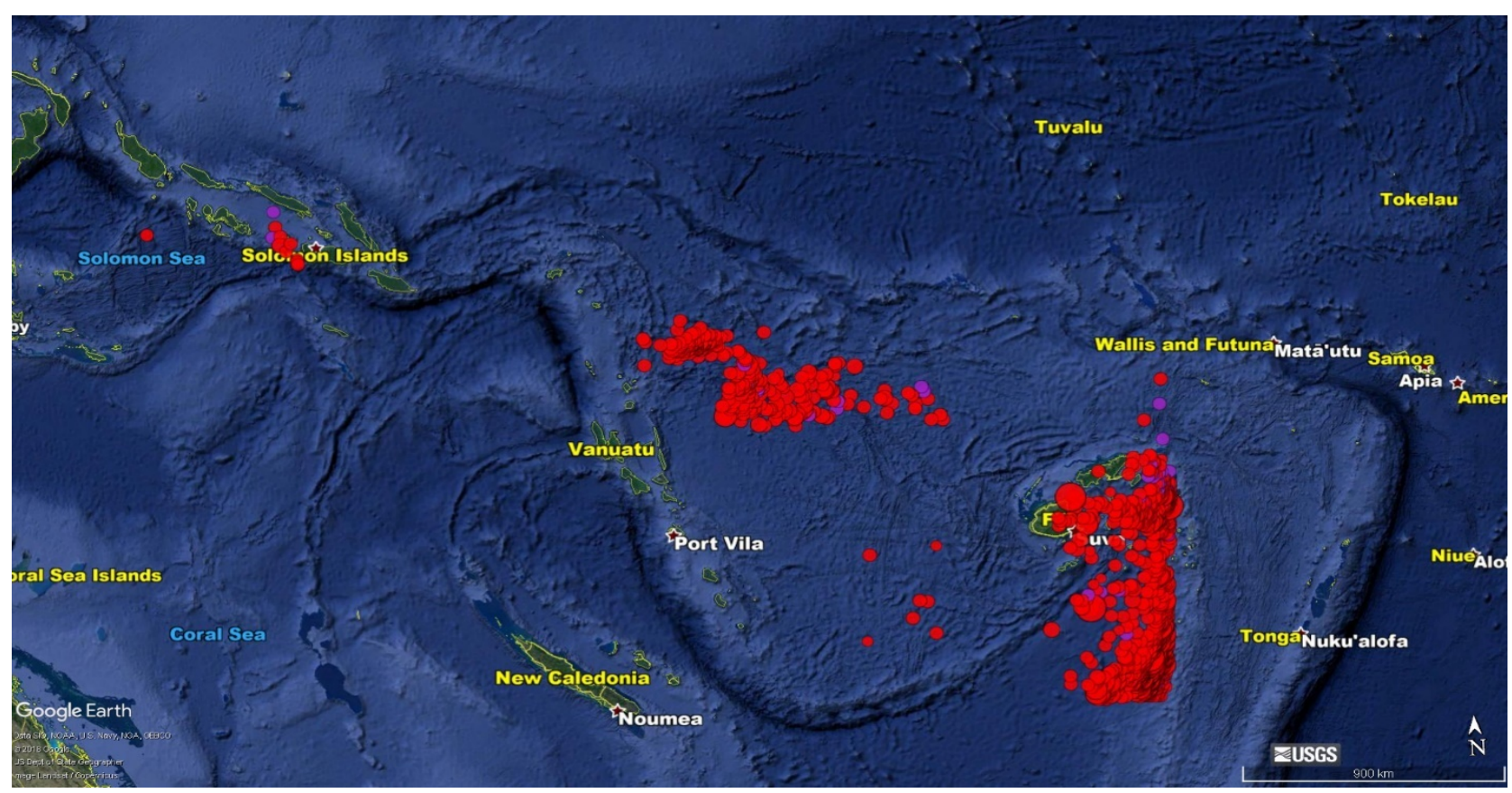

Figure 3. This location is South Pacific region, the earthquakes ultra-deep are the ones with greatest depth worldwide.

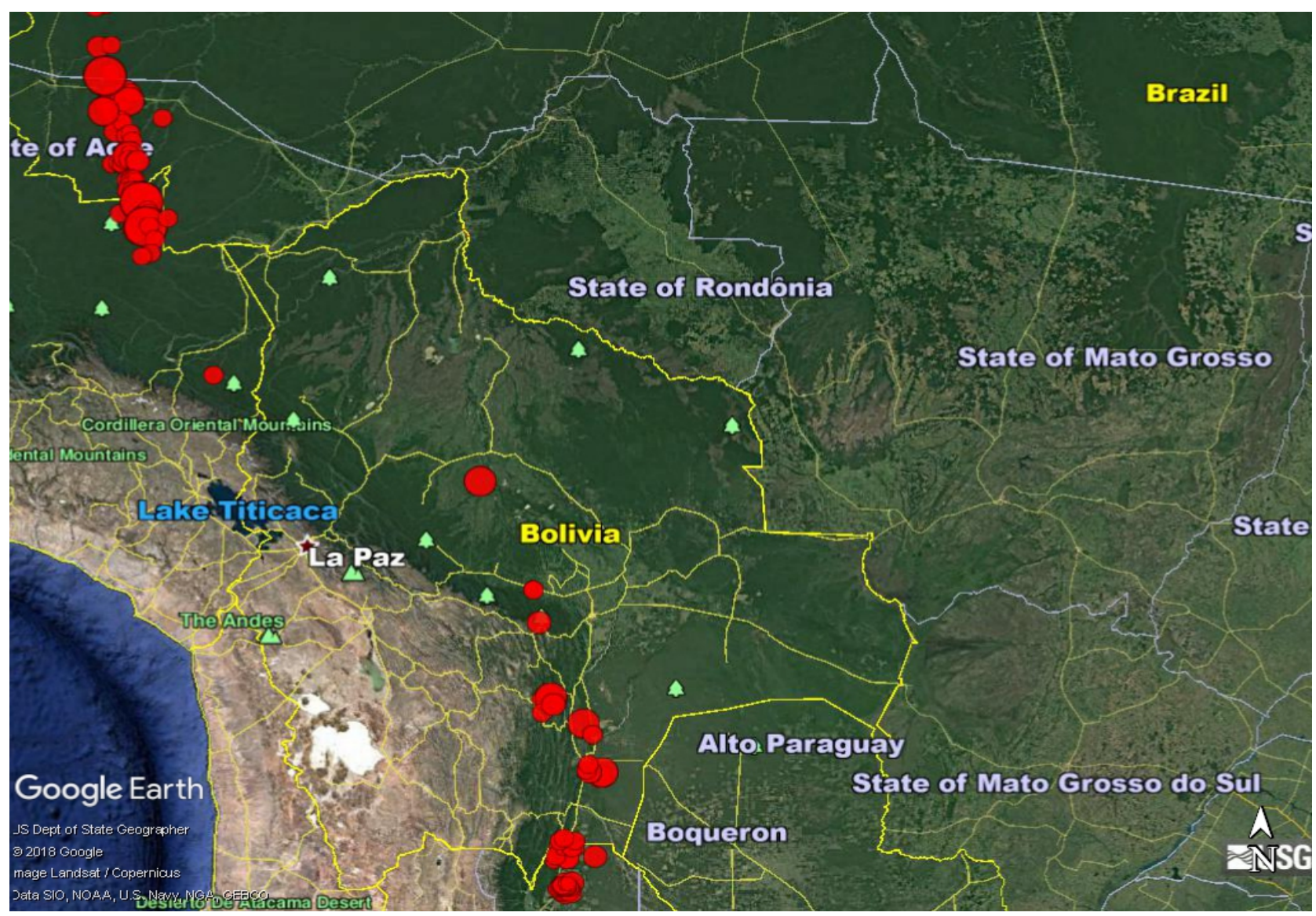

Figure 4. Localization of ultra-deep earthquakes in South America. 
Table 1. Northern and Southern Hemisphere limits for locations with earthquakes depth $\geq 500 \mathrm{~km}$. Observe that Philippines was separated due to the high rate of UDQ.

\begin{tabular}{cc}
\hline Northern Hemisphere & Coordinates \\
\hline North Pacific & $58.076 \mathrm{~N}, 0.70 \mathrm{~S},-132.891 \mathrm{E},-260.156 \mathrm{~W}$ \\
Philippines & $24.035 \mathrm{~N}, 2.62 \mathrm{~S}, 138.184 \mathrm{E}, 112.852 \mathrm{~W}$ \\
Southern Hemisphere & $1.055 \mathrm{~N},-50.753 \mathrm{~S}, 132.891 \mathrm{E},-260.152 \mathrm{~W}$ \\
South Pacific & $14.605 \mathrm{~N},-71.762 \mathrm{~S},-20.391 \mathrm{E},-109.688 \mathrm{~W}$ \\
South America &
\end{tabular}

The seasons data for the Northern and Southern Hemispheres is displayed in Table 2. Although part of the Philippines is close to the Equator it is part of the Northern Hemisphere to simplify calculations.

Observe the dates for North Hemisphere for Spring, Summer, Fall and Winter, corresponds to the Fall, Winter, Spring and Summer at the South Hemisphere.

The next sections will investigate each of the primary locations. First, the regions in the Northern Hemisphere, and later the two regions in the Southern Hemisphere.

\section{METHOD USED}

Our method to determine if earthquakes increase, decrease or remain constant in each region and depth is the following:

First, the areas with occurrences of earthquakes below $500 \mathrm{~km}$ were defined. We divided into four central areas, North Pacific (Alaska, Japan, and Russia), Philippines, South Pacific (Australia, Fiji, Indonesia, Samoa, New Zealand, Vanuatu) and South America. In these locations, we collected data on quakes of magnitude $\geq$ M2.5 at depths $\geq 500 \mathrm{~km}$ during the period 1996-2017. The period is eighteen years and still comprises two Solar maxima in 2000 and 2014. We constructed tables of $\mathrm{N}$ values for each year searched and determined the average number of events per year by dividing the sum of all recorded events by 18 .

\subsection{Construction of Plots and Tables}

The dataset comprises earthquakes recorded during the period 1996-2017. The data values were $y_{1}=$ data recorded in the first-year level $\mathrm{n}($ depth $\geq 500 \mathrm{~km})$ in the region $\mathrm{X}(\mathrm{A}, \mathrm{B}, \mathrm{C}, \mathrm{D})$.

$$
\sum_{n 0}^{n n} Y n=y n 0+y n 1+\cdots y n n
$$

where $n=1999 \cdots 2017$, and $n$ ' is 18 years.

The mean is defined as

$$
\text { Mean }=M=\frac{\sum_{n 0}^{n n} Y n}{18}
$$

Data value - Mean $=Y n^{\prime} \quad[3]$.

If $\mathrm{Y}_{n}^{\prime}>\mathrm{M}$, the value is higher than one during that year and it means the number of earthquakes exceeds the average. On the other hand, if $\mathrm{Y}_{n}^{\prime}<M$ the number will be less than one during that year, indicating that the number of earthquakes was below the average. It is also possible to have a result of zero (though this was not common in our dataset), which would mean there was no variation in relation to the average of all years. Those calculations are made for each of the seasons and years for the locations analyzed.

The next sections explain the results found and discuss the variations in earthquakes by year and across the entire period. 
Table 2. Seasonal divisions for Northern and Southern Hemispheres.

\begin{tabular}{cccc}
\hline North Hemisphere & Period & South Hemisphere & Period \\
\hline Spring & March 1-May 31 & Spring & Sept. 1-Nov. 30 \\
Summer & Jun. 1-Aug. 31 & Summer & Dec. 1-Feb. 28 \\
Fall & Sept. 1-Nov. 30 & Fall & March 1-May 30 \\
Winter & Dec. 1-Feb. 28 & Winter & Jun. 1-Aug. 31 \\
\hline
\end{tabular}

\subsection{North Pacific Seasonal Fluctuations}

This section examines the seasonal activity in the North Pacific area during the period 1999-2017 across four seasons. The period is short but provides enough information to consider two maximum solar cycles as in our earlier studies $[1,2]$.

The results in Figure 5 and Table 3 show the variation, enhancement, or decrease of tremors in each year. Figure 5 was constructed by dividing the specific number of events each year by the average events over all years.

We identified a slight rise in events during Spring or Fall for this region. However, in some years the number of tremors increased during the Summer, as in 2002, 2004, and 2008, or throughout the Winter, as in 2005, 2013, 2014, and 2016. From 2009 to 2012 all seasons reduced the activity in the area.

One possible explanation for the lower activity during 2009-2012 was a minimum in the Solar activity, as discussed in another paper [2]. This is the first evidence that external causes may be able to change the occurrences of UDQs.

Next, we examine the Philippines region in the Northern Hemisphere.

\subsection{Philippines and Season Variations}

Table 4 and Figure 6 show that the Philippines are one of the most unstable regions for UDQs, independent of season. Spring and Fall are sharing the same percentage of events in average most during years for minimum of the cycle as in Figure 6 during the period 2009-2012. Although a peak occurred during the 2010, Summer and it is the season in Philippines where have the highest variations as we are going to show.

Winter had the fewest changes and in 2012 had zero variation. Because this region is the nearest to the Equator (2.62 S), seasons behaving slightly different from other locations cited. However, our best area of activity is just northeast of the Philippines. In the next paragraphs, we will discuss the impact of the season on the Philippines compared with other regions.

\subsection{South Pacific and Season Expectations}

Table 5 and Figure 7 show the seasonal variation during the period 1999-2017. We observe a slight enhancement for tremors during the Spring and Fall. As in the North Pacific, events decreased in the period 2009-2012; in the Summer of 2012, we even found a total lack of activity in this area.

The subsequent year, 2013, brought an enhancement of events during the Summer, which coincides with the same increase during Winter in the North Pacific. This was the same period of the year for both Hemispheres.

In the interval 2014-2017, events were augmented during all seasons except the Winter. Similar behavior between both Hemispheres in the Pacific shows a possible connection between the two. Overall, they show identical activity for opposite seasons as we expected. This correspondence occurred mainly between Summer and Winter. Events occurring in North Pacific shows reciprocity for ones in the South Pacific, although Spring at the North corresponds to the Fall in the South. See Table 2. 


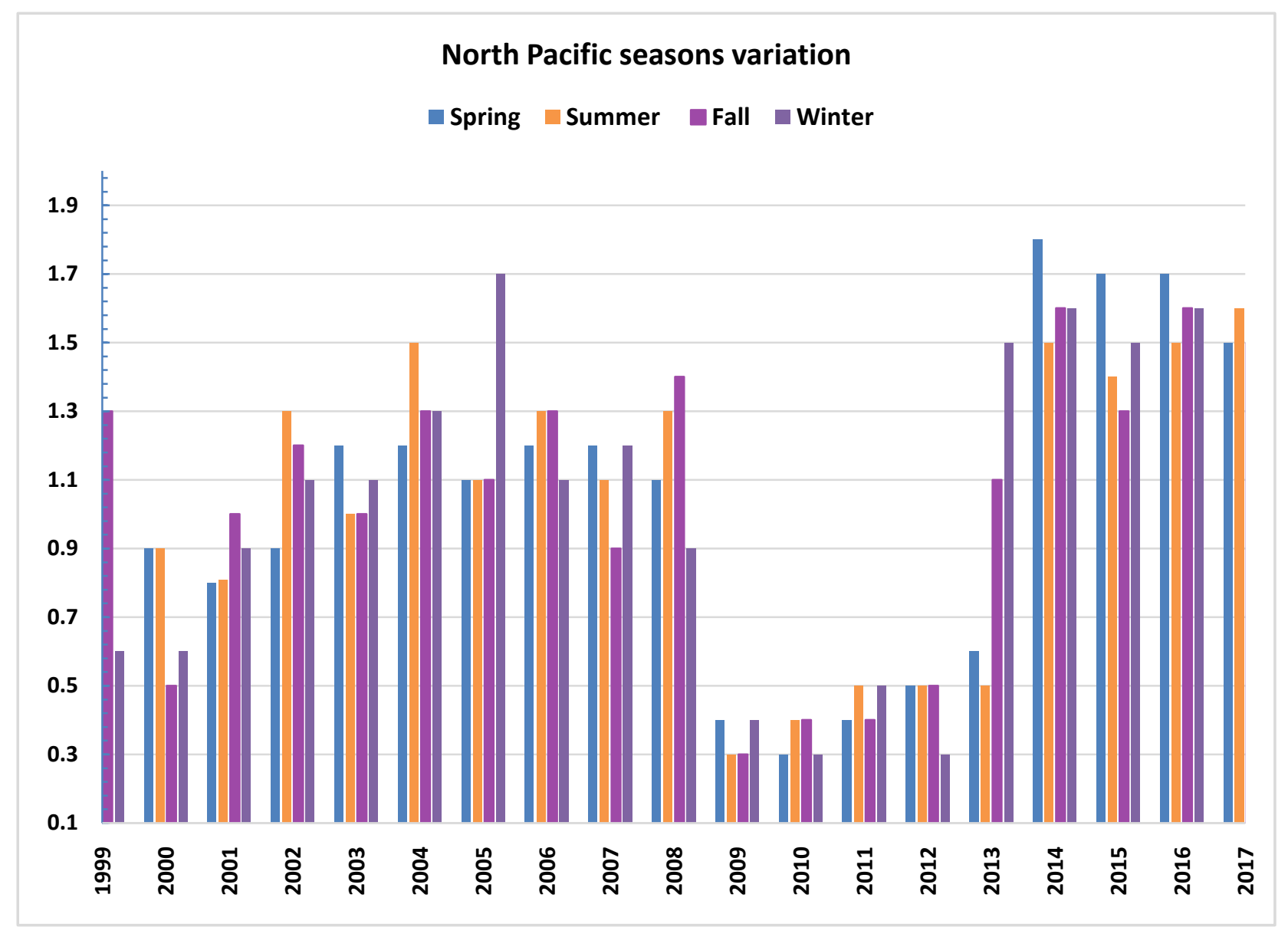

Figure 5. Earthquakes ultra-deep seasonal variation period 1999-2017, North Pacific region, it displays the Table [3].

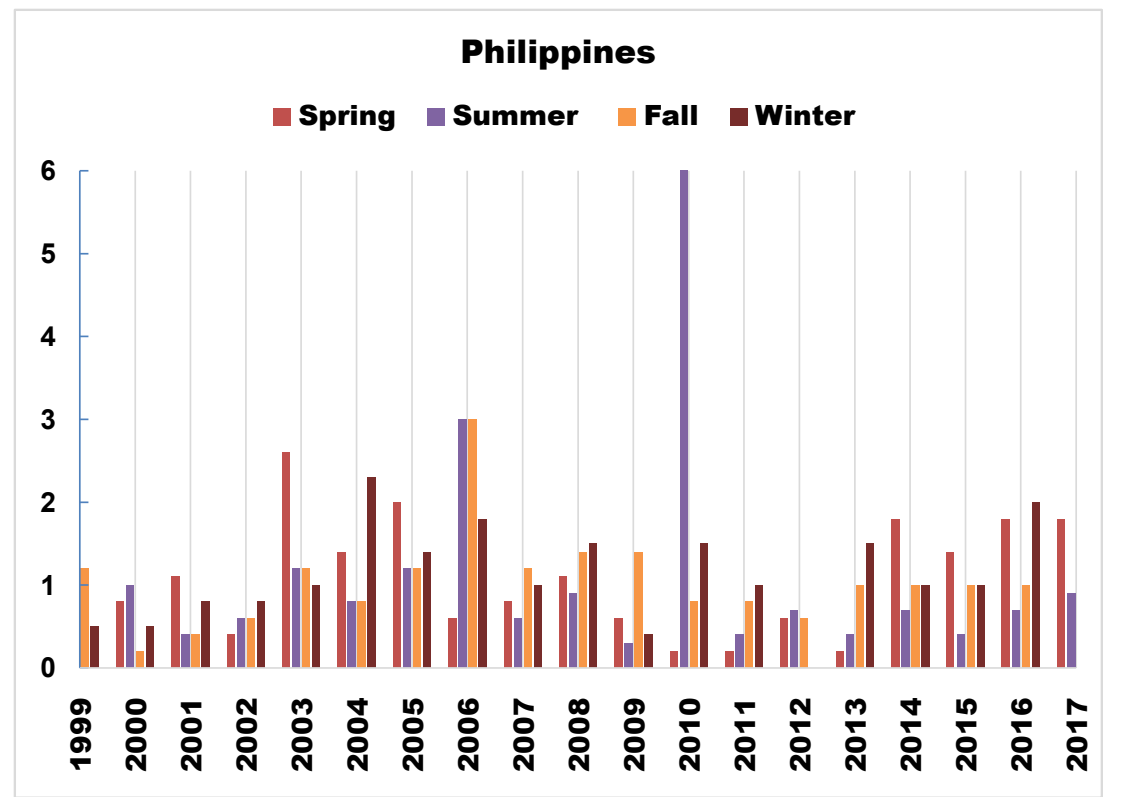

Figure 6. UDQ in the Philippines region, it is the plot representing Table [4]. 


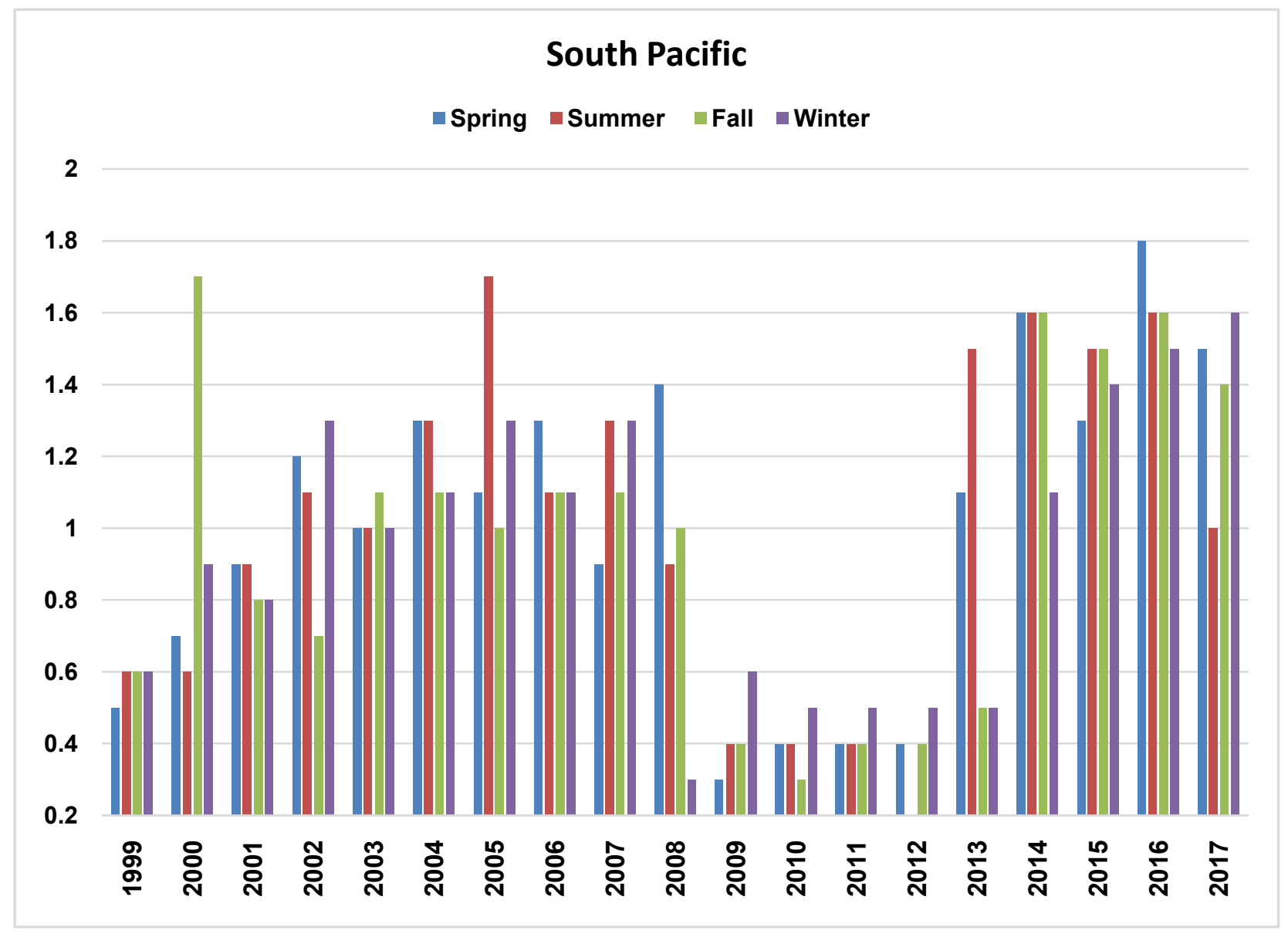

Figure 7. Southern Pacific seasonal variations, depths $\geq 500 \mathrm{~km}, \mathrm{M} \geq 2.5$. Included Australia Indonesia, Fiji, Samoa, New Zealand, Vanuatu represents Table [5].

\subsection{South America Seasonal Variations}

The last region studied was South America. The conditions for the search are like the other locations, focused on earthquakes at depths $\geq 500 \mathrm{~km}$, magnitude $M>2.5$. Activity by season is provided in Table 6 and Figure 8. The plot is constructed following the same method as the first ones, taking the average of events for each year during all seasons.

The first critical issue in this area is the activity at intraplate locations, which we did not find in other regions analyzed. However, events increase the most as in other areas during Spring and Fall. There is also an exception in the spring of 2015, when the seasonal enhancement was almost six times the average, followed by the summer with events increasing three times over the standard pattern. This region is also unique in that in some years it did not present any tremors in certain seasons, including 2000 (Spring/Summer), 2003 (Spring), 2004 (Winter), 2005 (Summer), 2010 (Winter), 2011 (Summer), and 2017 (Spring/Fall). South America presented an average number of tremors during Fall and Winter for most years, but also an anomalous increase during the Winter for some years $(2000,2003,2007,2012)$. The biggest discrepancy appeared during the Spring in 2015 and 2016, and a total lack of activity for Spring and Fall in 2017.

\section{ULTRA-DEEP EVENTS VARIABILITY AND SEASONS}

Now, we consider the percentage variation for each season and region we analyzed. This is an important step in measuring the possible influence of seasons on UDQs in each location. To construct those 
Table 3. North Pacific variations during seasons.

\begin{tabular}{ccccc}
\hline & North & Pacific & \\
\hline Year & Spring & Summer & Fall & Winter \\
\hline 1999 & 0.7 & 0.6 & 1.3 & 0.6 \\
2000 & 0.9 & 0.9 & 0.5 & 0.6 \\
2001 & 0.8 & 0.81 & 1 & 0.9 \\
2002 & 0.9 & 1.3 & 1.2 & 1.1 \\
2003 & 1.2 & 1 & 1 & 1.1 \\
2004 & 1.2 & 1.5 & 1.3 & 1.3 \\
2005 & 1.1 & 1.1 & 1.1 & 1.7 \\
2006 & 1.2 & 1.3 & 1.3 & 1.1 \\
2007 & 1.2 & 1.1 & 0.9 & 1.2 \\
2008 & 1.1 & 1.3 & 1.4 & 0.9 \\
2009 & 0.4 & 0.3 & 0.3 & 0.4 \\
2010 & 0.3 & 0.4 & 0.4 & 0.3 \\
2011 & 0.4 & 0.5 & 0.4 & 0.5 \\
2012 & 0.5 & 0.5 & 0.5 & 0.3 \\
2013 & 0.6 & 0.5 & 1.1 & 1.5 \\
2014 & 1.8 & 1.5 & 1.6 & 1.6 \\
2015 & 1.7 & 1.4 & 1.3 & 1.5 \\
2016 & 1.7 & 1.5 & 1.6 & 1.6 \\
2017 & 1.5 & 1.6 & 1.5 & 1.1 \\
\hline
\end{tabular}

plots, we tallied the events during the Spring, Summer, Fall, and Winter seasons for each year in the period 1999-2017, then expressing that distribution as a percentage of the total UDQ events for the year. The North Pacific is displayed in Figure 9, showing that Summer has a slight increase compared to the other seasons. Spring is also slightly elevated, but in general the four seasons had a balanced number of tremors in the area.

Figure 10 displays a similar percentage variation in the Philippines, which is one of the most active locations around the world. The plot shows that Summer is the most important season in this area with $33 \%$ of activity remember that the Sun is located at the aphelion in relation to the Earth, Spring and Fall are like each other, and the Winter shows a decrease in tremors.

The next plot, Figure 11, shows the South Pacific variation. The four seasons show almost equal percentages, with a small increase during the Spring. The season is South Pacific are distributed as Spring $26 \%$, Summer $24 \%$ and Fall and Winter both $25 \%$. Besides the difference between Spring and Summer is just 2\% in this area. If recurred at Figure 7 there was a period 2009-2012 when all the seasons decreased in number and afterwards most of the season enhanced again. However with a small decreased in 2013 for Winter and Fall. Overall, the variations were not enough to make the percentage of quakes in this area do much difference between each other.

The next plot, Figure 12 displays South American seasons, and it was clear that the Spring has a significant increase in tremors at this location. The next most active is the Fall, and Summer and Winter had a similar performance.

Ultra-deep earthquakes are normally located at the subduction zones. In this location, the UDQs are occurring intraplate instead. Thus, we suggested the possibility of an internal mechanism that can trigger those deep depth tremors in the area [4]. 
Table 4. Philippines region activity during season in the period mentioned.

\begin{tabular}{|c|c|c|c|c|}
\hline \multicolumn{5}{|c|}{ Philippines } \\
\hline Year & Spring & Summer & Fall & Winter \\
\hline 1999 & 0.4 & 0.3 & 1.2 & 0.5 \\
\hline 2000 & 0.8 & 1 & 0.2 & 0.5 \\
\hline 2001 & 1.1 & 0.4 & 0.4 & 0.8 \\
\hline 2002 & 0.4 & 0.6 & 0.6 & 0.8 \\
\hline 2003 & 2.6 & 1.2 & 1.2 & 1 \\
\hline 2004 & 1.4 & 0.8 & 0.8 & 2.3 \\
\hline 2005 & 2 & 1.2 & 1.2 & 1.4 \\
\hline 2006 & 0.6 & 3 & 3 & 1.8 \\
\hline 2007 & 0.8 & 0.6 & 1.2 & 1 \\
\hline 2008 & 1.1 & 0.9 & 1.4 & 1.5 \\
\hline 2009 & 0.6 & 0.3 & 1.4 & 0.4 \\
\hline 2010 & 0.2 & 6 & 0.8 & 1.5 \\
\hline 2011 & 0.2 & 0.4 & 0.8 & 1 \\
\hline 2012 & 0.6 & 0.7 & 0.6 & 0 \\
\hline 2013 & 0.2 & 0.4 & 1 & 1.5 \\
\hline 2014 & 1.8 & 0.7 & 1 & 1 \\
\hline 2015 & 1.4 & 0.4 & 1 & 1 \\
\hline 2016 & 1.8 & 0.7 & 1 & 2 \\
\hline 2017 & 1.8 & 0.9 & 0.8 & 1.8 \\
\hline
\end{tabular}

Comparing Figure 9 and Figure 11, detailing North Pacific and South Pacific events, the ultra-deep earthquakes at these locations act as a mirror of each other during most of the period observed. For example, if the North Pacific increased the number of quakes during Spring/Summer (see Table 2), the South Pacific would show similar activity during the corresponding Fall/Winter during the same months.

Nevertheless, both hemisphere locations presented a long decay of activity in the period of 2009-2013 and suddenly showed enhancement during the northern Winter with a correspondent increase in the South Pacific during the Summer, (see Table 2). The years after 2014 continue displaying the same pattern of northern and southern variation happening during the same period of the year. In Figure 11 we see that the Philippines generally follows the pattern of the North Pacific: the season with the largest variation is Summer with 33\%, although North Pacific Summer variation is only 29\%. In Winter the correspondence is closer, when the events are $19 \%$ of the total in Philippines and $21 \%$ in the North Pacific. The South Pacific activity was spread almost evenly through all seasons, with a small increase for the Spring.

South America does not behave similarly to the other three areas examined. Earthquakes increase during Autumn/Winter in some years, and in others in Spring/Summer without showing any preference for one season over another. There were also seasons in some of those years that presented no statistically measurable variation, for example, 2000, 2001, 2003-2005, 2010, 2011, and 2017. The lack of variation in these years for some season does not mean a complete absence of tremors but they may have been lower than the average. These results appear to confirm the hypothesis that South America presents an anomaly in the lithosphere that remains unknown. On the other hand, it seems that tremors happening in the North Pacific may somehow affect the South Pacific at this depth $(\geq 500 \mathrm{~km})$, suggesting an internal or external connection between the two, already mentioned in our last paper. 
Table 5. South Pacific (Australia, Fiji, Indonesia, Samoa, New Zealand, Vanuatu) activity during seasons.

\begin{tabular}{ccccc}
\hline & South & Pacific & & \\
\hline Year & Spring & Summer & Fall & Winter \\
\hline 1999 & 0.5 & 0.6 & 0.6 & 0.6 \\
2000 & 0.7 & 0.6 & 1.7 & 0.9 \\
2001 & 0.9 & 0.9 & 0.8 & 1.3 \\
2002 & 1.2 & 1.1 & 0.7 & 1 \\
2003 & 1 & 1 & 1.1 & 1.1 \\
2004 & 1.3 & 1.3 & 1.1 & 1.3 \\
2005 & 1.1 & 1.7 & 1 & 1.1 \\
2006 & 1.3 & 1.1 & 1.1 & 1.3 \\
2007 & 0.9 & 1.3 & 1.1 & 0.3 \\
2008 & 1.4 & 0.9 & 1 & 0.6 \\
2009 & 0.3 & 0.4 & 0.4 & 0.5 \\
2010 & 0.4 & 0.4 & 0.3 & 0.5 \\
2011 & 0.4 & 0.4 & 0.4 & 0.5 \\
2012 & 0.4 & 0.2 & 0.4 & 0.5 \\
2013 & 1.1 & 1.5 & 0.5 & 1.1 \\
2014 & 1.6 & 1.6 & 1.6 & 1.4 \\
2015 & 1.3 & 1.5 & 1.5 & 1.5 \\
2016 & 1.8 & 1.6 & 1.6 & 1.6 \\
2017 & 1.5 & 1 & 1.4 &
\end{tabular}

\section{FINAL DISCUSSION}

The paper examined a possible connection between ultra-deep tremors and seasons, based on observed enhancements and disparities. The results pointed out that earthquake events tend to increase during Spring and Fall for all regions studied.

The rises during Summer or Winter in the North Pacific correspond to the same upsurges during the Winter or Summer in the Southern Pacific, see Table 2 for clarification. South America shows different development of ultra-deep earthquakes; our results did not show tremors in some of the seasons examined in South America, which is quite a different outcome compared with the three other regions.

The explanation for events during Spring and Fall is due to the Earth's position in relation to the Sun. During those seasons the Sun's power is directed toward the Earth's equator. Both Hemispheres receive the same amount of solar energy during those seasons. In January, which is Summer in the Southern Hemisphere, the Earth is in the perihelion the nearest position Earth reaches to the Sun and supposed that the solar energy faces to the South more, it corresponds to the Summer at the South Hemisphere. According to this pattern, we would expect more ultra-depth earthquakes at those times in the Southern Hemisphere. But the expect result did not occur and the South Hemisphere Figure 11, have spread the tremors occurrences almost in the same percentages for all seasons. The only area that had a great increase of tremors in the Summer was around Philippines, what is coincides to be at the North Hemisphere and the Earth's position in relation to the Sun is in the aphelion.

\section{CONCLUSIONS}

Our results indicated that ultra-deep earthquakes showed a slight increase or decrease during Spring and Fall worldwide. Furthermore, activity in the North Pacific Ocean shows a strong connection to quakes 
Table 6. South America region activity during seasons. Observe the lack of activity during some seasons in this location.

\begin{tabular}{ccccc}
\hline & South & America & \\
\hline Year & Spring & Summer & Fall & Winter \\
\hline 1999 & 0.5 & 1 & 0.3 & 1 \\
2000 & 0 & 0 & 1 & 1.5 \\
2001 & 0 & 0 & 1.7 & 1 \\
2002 & 0.5 & 1 & 1.5 & 1 \\
2003 & 0 & 1.5 & 1 & 2.5 \\
2004 & 0.8 & 1.5 & 0.7 & 0 \\
2005 & 1 & 0 & 2 & 0.5 \\
2006 & 1 & 1 & 1 & 1 \\
2007 & 0.5 & 1.5 & 0.7 & 1.5 \\
2008 & 1.3 & 1.5 & 0.3 & 0.5 \\
2009 & 0.5 & 1 & 1 & 1 \\
2010 & 0.5 & 2 & 1.5 & 0 \\
2011 & 0.8 & 0 & 1.5 & 1 \\
2012 & 0.8 & 1.5 & 0.3 & 2.5 \\
2013 & 0.3 & 1 & 1 & 0.5 \\
2014 & 1.3 & 0.5 & 1 & 1 \\
2015 & 6 & 3 & 1 & 0.5 \\
2016 & 1.8 & 1.5 & 0 & 1 \\
2017 & 0 & 0.5 & & 0.5 \\
\hline
\end{tabular}

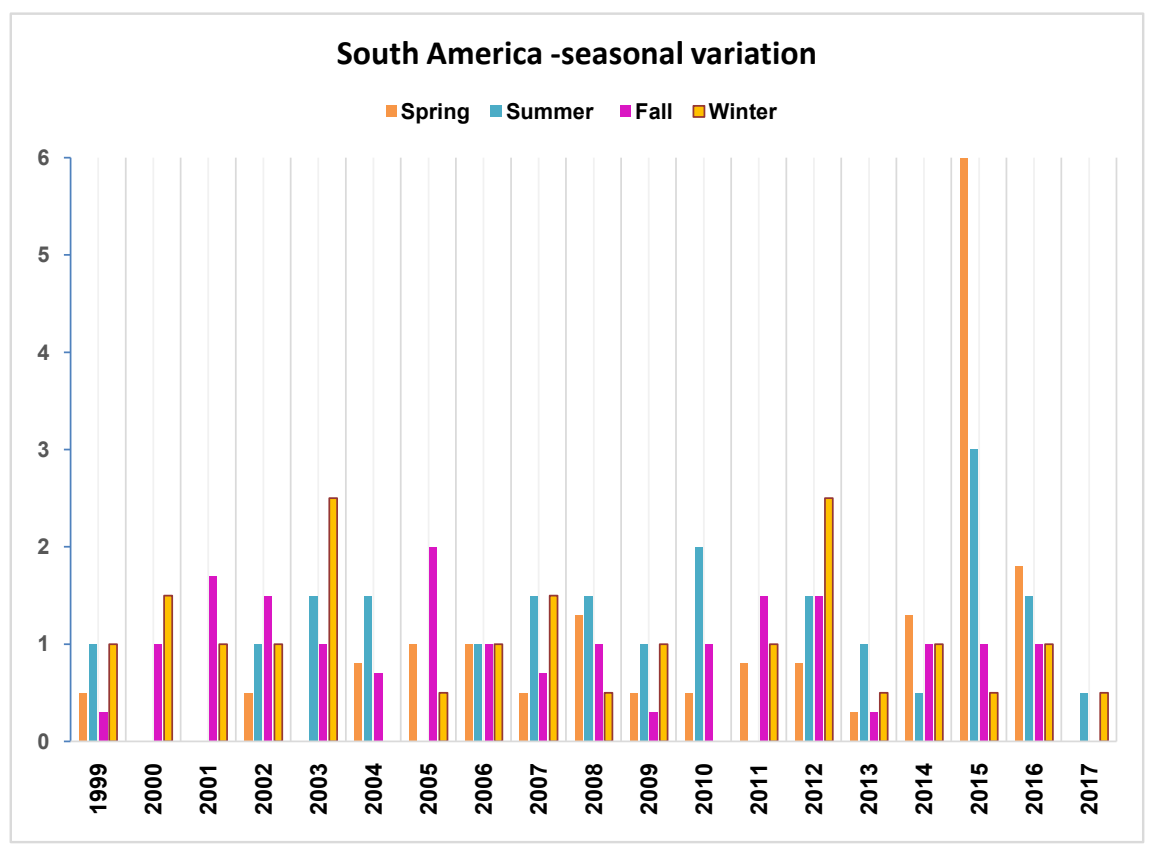

Figure 8. South America seasonal variation, for the ultra-depth earthquakes $>500 \mathrm{~km}, \mathrm{M}>2.5$. 


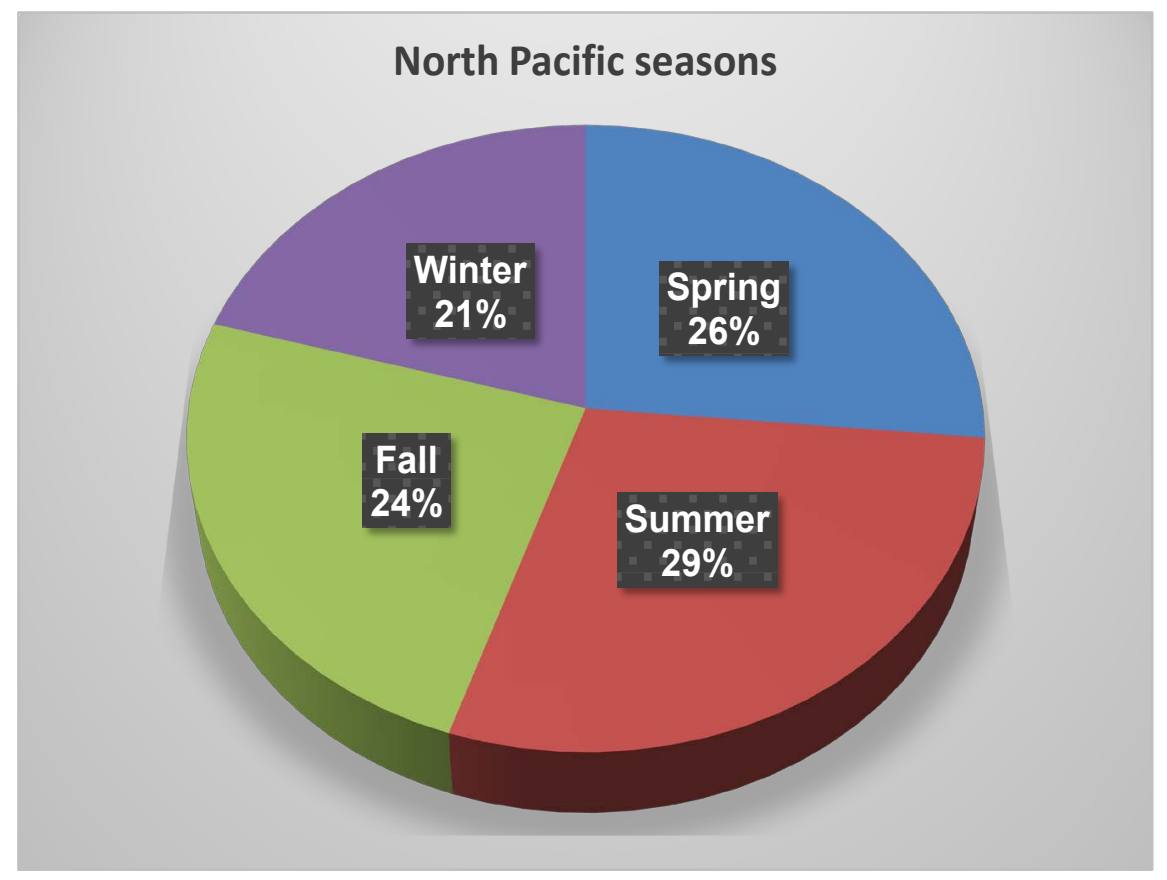

Figure 9. The seasonal variation during the period 1999-2017 is shown on the picture. The season more active is the Summer, the less is the Winter. However, the calculations must cover averages what would be considered as some years have extreme action in the Summer and other much lower. The seasons at North Pacific are the opposite in South Pacific.

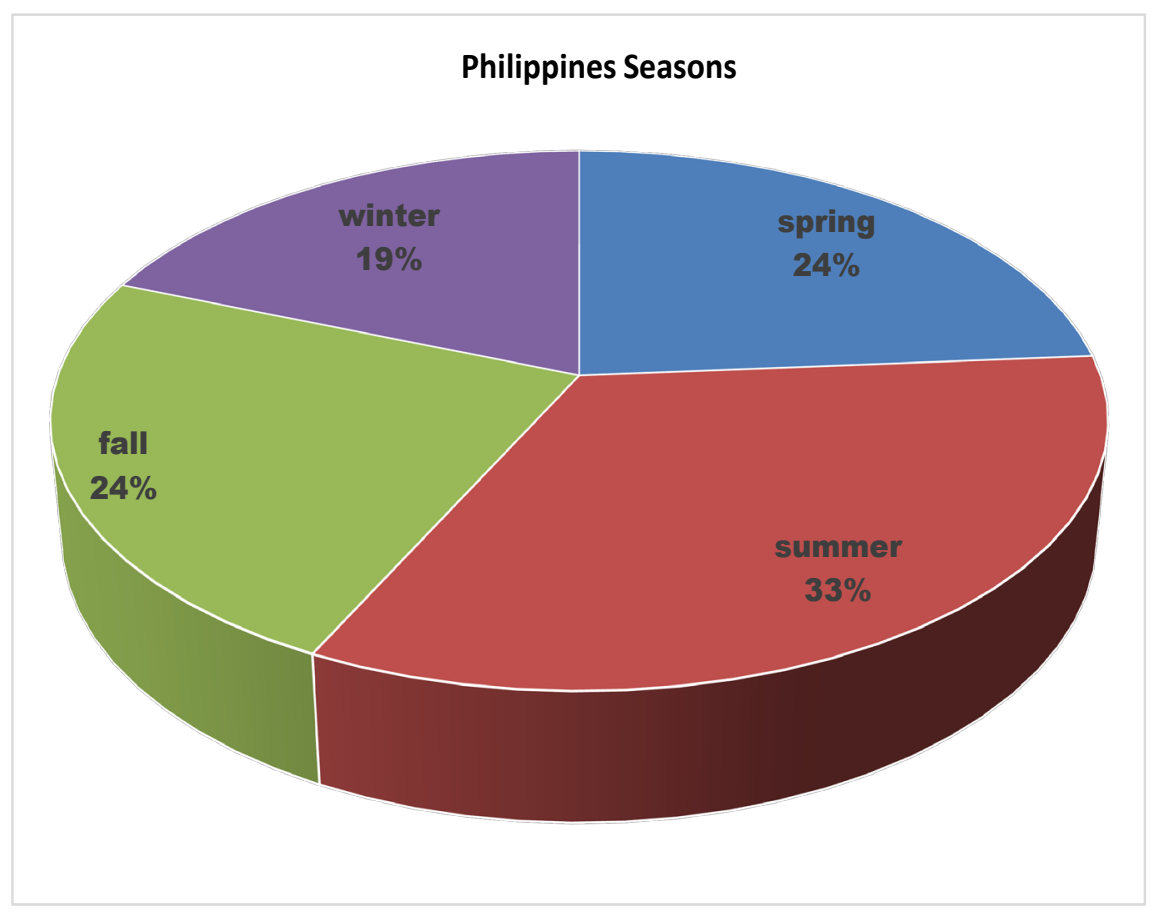

Figure 10. Philippines variations during the seasons. 


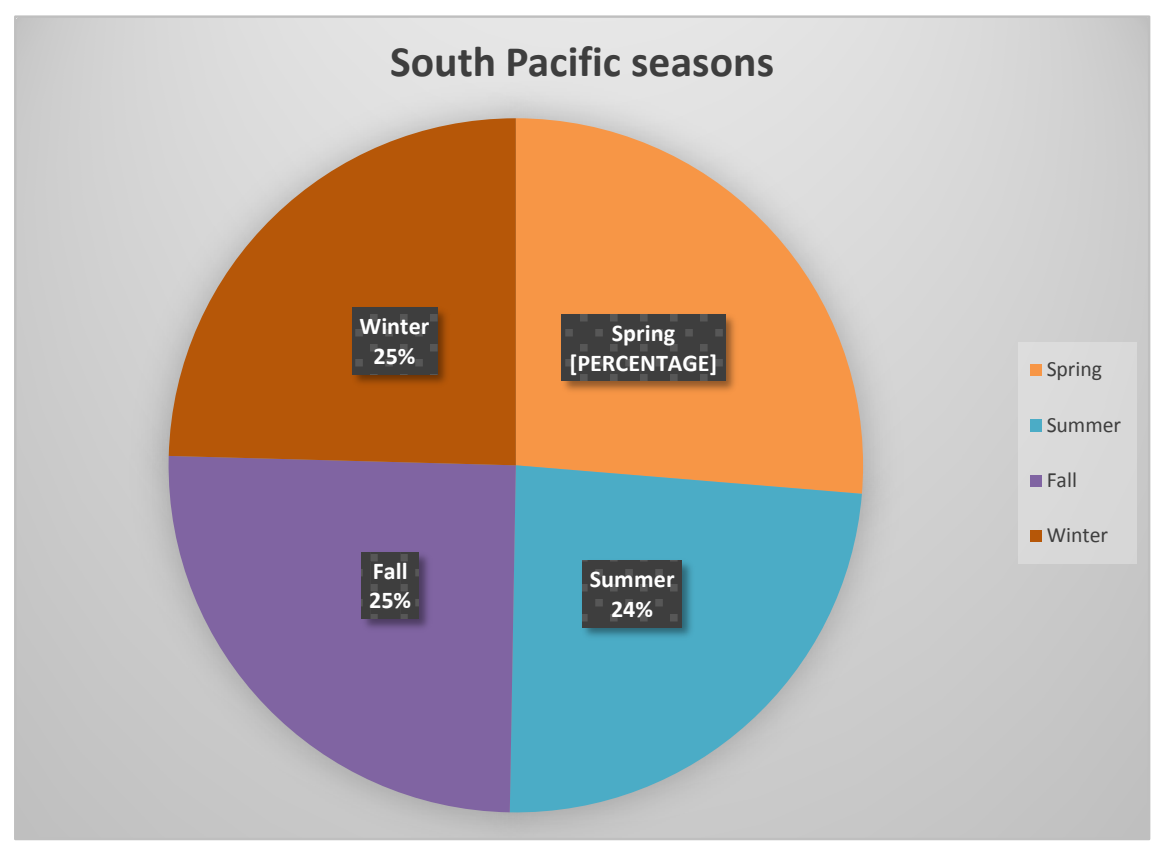

Figure 11. South Pacific showing a balanced distribution of events for the four seasons. Although the Spring is a little more active.

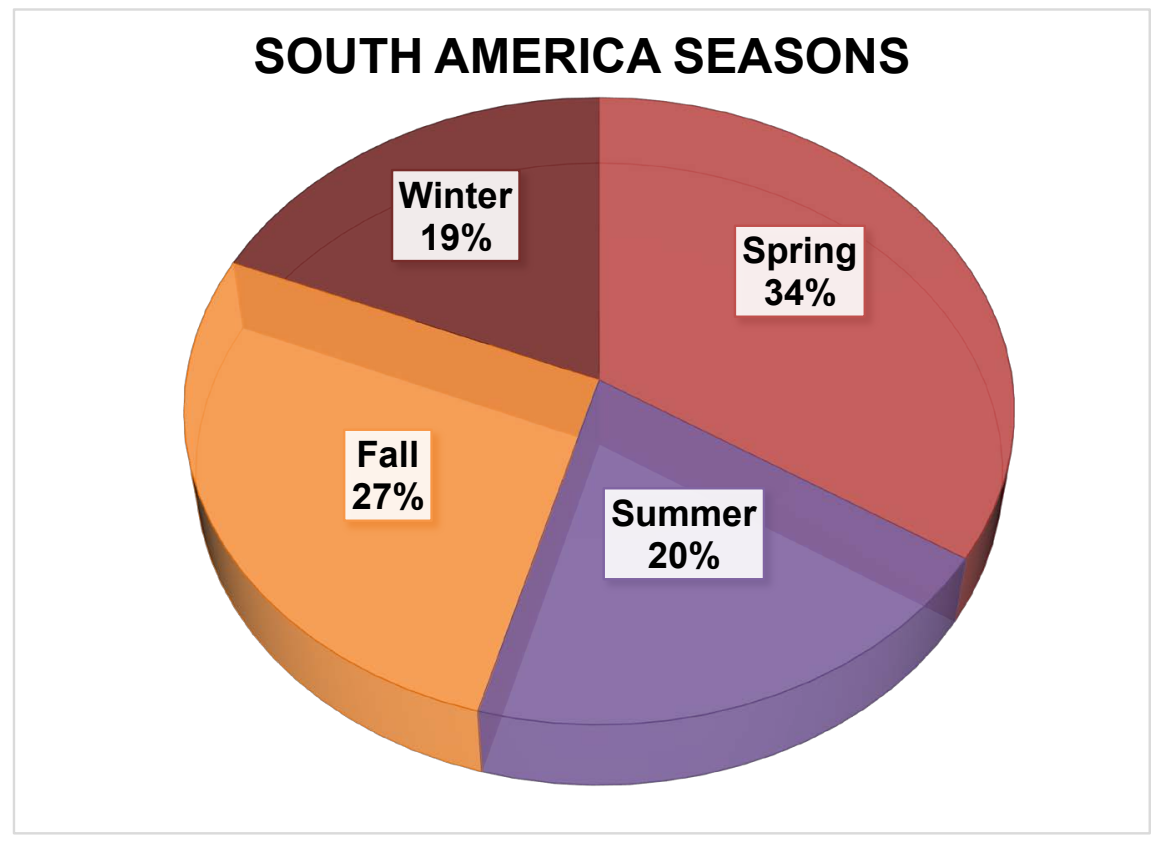

Figure 12. South America showing a huge enhancement of events for Spring followed by Fall.

in the Southern Pacific Ocean; earthquake occurrences in the North Pacific Hemisphere during a given season will match an increase in tremors in the South Pacific during the opposite season independent from the position relation to the Sun. It indicates that independent of the seasons, the occurrences of UDQ's are alike to be connecting North and South Pacific by internal reasons not external.

The Philippines shows the greatest increases during the Spring and Summer though with some excep- 
tions all the seasons have very good earthquakes activity. South American seasonal variation has independent results not correlated with the other three areas. This region has been studied in a previous paper [4].

\section{ACKNOWLEDGEMENTS}

Paul Lindell, for the edition and corrections on this paper.

\section{CONFLICTS OF INTEREST}

The authors declare no conflicts of interest regarding the publication of this paper.

\section{REFERENCES}

1. Hagen, M. and Azevedo, A. (2017) Possible Connections between X-Solar Flares and Worldwide Variations in Seismicity Enhancement. Natural Science, 9, 20 p.

2. Hagen, M. and Azevedo, A. (2017) Sun-Moon-Earth Interactions, External Factors for Earthquakes. Natural Science, 9, 162-180.

3. Hagen, M. and Azevedo, A. (2016) Gravitational Moon-Earth Forces, Triggering Earthquakes in Subduction Zones. Journal of Geography, Environment and Earth Sciences International, 8, 1-14.

4. Hagen, M. and Azevedo, A. Deep and Ultra-Deep Earthquakes Worldwide, Possible Anomalies in South America. (Submitted)

5. Oliver, J. and Isacks, B. (1967) Deep Earthquake Zones, Anomalous Structures in the Upper Mantle, and the Lithosphere. Journal of Geophysical Research, 72, 4259-4275.

6. Stark, P.B. and Frolich, C. (1985) The Depths of the Deepest Deep Earthquakes. Journal of Geophysical Research, 90, 1859-1869. https://doi.org/10.1029/JB090iB02p01859

7. https://earthquake.usgs.gov/earthquakes/search/

8. http://ds.iris.edu/wilber3/find_event

9. https://www.emsc-csem.org/Earthquake/?filter=yes 